\title{
Loracarbef Anhydrous
}

National Cancer Institute

\section{Source}

National Cancer Institute. Loracarbef Anhydrous. NCI Thesaurus. Code C61815.

An anhydrous form of loracarbef, a semi-synthetic, broad-spectrum, beta-lactamase resistant, second-generation cephalosporin antibiotic derived from cephasporium. 